\title{
¿PROTOCOLO? 0 ¿RESPETUOSA Y ENTRAÑABLE SOLIDARIDAD HACIA EL ENFERMO?
}

\author{
$M^{a}$ Teresa Miralles Sangro \\ Profesora Titular de la Universidad de Alcalá
}

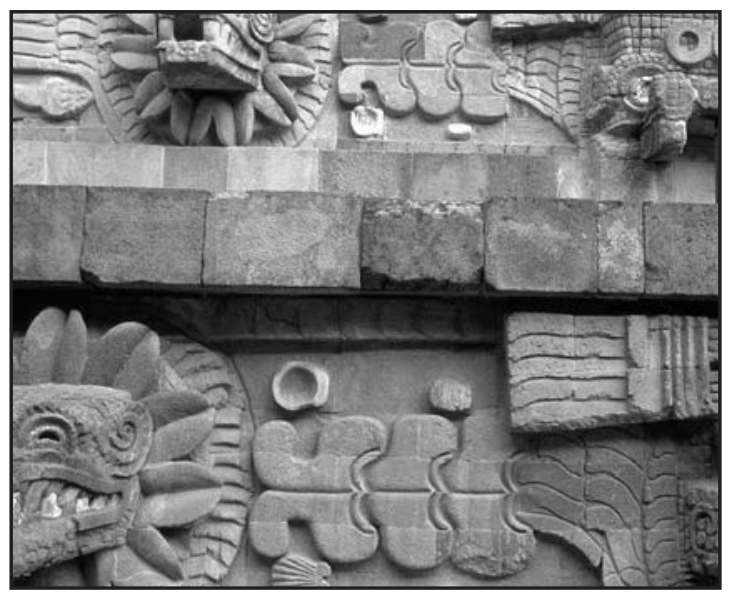

PROTOCOL? OR DEFERENTIAL AND DEEP SOLIDARITY TOWARDS ILL PATIENTS?

\section{SUMMARY}

$\mathrm{P}$ ortraits of sick people showing their illnesses were not really frequent along XIX century, compared to the full production of Spanish painters. This premise together with my own surprise at the discovering of the piece of art I herewith consider, were determinant on my decision to develop the present study. The piece of art, is a portrait by José Roldán painted around 1864, Her Majesty Queen Elizabeth II in the act of kissing the hand of the poorest and eldest man in the Charity Hospital of Seville.

The reason for this study goes around the description of attitudes and behaviour towards the ill patient and his/her care taker in the Elizabethan Spanish period.

It is a descriptive and interpreting study where characters appearing on the stage would be considered according to the events they are suppose to take part in. Who they are, why they are where they are and what sort of role they do perform.

The piece of work was exhibited by Roldán in the National Exhibition 1864. It could be regarded within a Seville genre presenting a society of extreme Christian habits and their interest in religious processions, charity and festivity and civil celebrations.

In the analyzed portrait nothing is merely accidental, those characters present must be present. Nursing, still voiceless at that time justifies punctually and clearly its presence there as there is an ill person who needs 'care'. The argument is the satisfaction of his vital needs be fulfilled.

key words: Nursing Care; Human care; Nursing history; Nursing as an Art; Art and care; Nursing presence; Iconography.

\section{RESPEITOSA E SIMPÁTICA SOLIDARIE- DADE PARA COM OS DOENTES}

\section{RESUMO}

representação artística da pessoa em sua
enfermidade, durante o século XIX, não é
muito freqüente, se se comparada com o total da produção dos pintores espanhóis. Esta premissa, junto com a surpresa do descobrimento da obra, foram os determinantes que nos moveram a este estudo. Trata-se de uma obra de josé roldán que realizou em 1864 e o pôs como nome sua majestade a rainha isabel ii no ato de beijar a mãe ao pobre mais antigo do hospital da caridade de sevilha.

A justificativa do trabalho gira em torno à descrição de atitudes e comportamento em direção ao enfermo e seu cuidador na espanha isabelina.

Trata-se de um estudo descritivo e interpretativo, no qual serão conectados os personagens que aparecem na cena com o objeto de entender o acontecimento que os cerca. Quem são, por que estão e que pael representam?

A obra foi apresentada por roldán em exposição nacional em 1864. Enquadra-se no gênero dos costumes de sevilha, o reflexo de uma socie- 
dade demarcada pela religiosidade com gosto pelas procissões e as obras de caridade, das festividades e celebrações cidadãs.

$\mathrm{Na}$ pintura analisada, a representação não é casual; estão todos os que são e são todos os que estão. A enfermagem, ainda sem vocês próprias que a expresem publicamente, justifica sua presença no fato de que há uma pessoa enferma e, neste caso, que necessita de seus cuidados. A satisfação de suas necessidades vitais é a argumentação.

Palavras-chave: cuiddos de enfermagem. Cuidado humanizado. História da enfermagem. Enfermagem na arte. Arte e cuidados. Representação da enfermagem. Iconografia.

\section{RESUMEN}

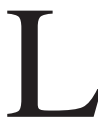

a representación artística de la persona en su enfermedad, durante el siglo XIX, no es muy frecuente si se compara con el total de la producción de los pintores españoles. Esta premisa, junto con la sorpresa del descubrimiento de la obra, fueron los determinantes que nos movieron a su estudio. Se trata de una obra de José Roldán que realizó ca. 1864 y le puso como nombre $\mathrm{Su}$ Majestad la reina Isabel II en el acto de besar la mano al pobre mas antiguo del hospital de la Caridad de Sevilla.

La justificación del trabajo gira en torno a la descripción de actitudes y comportamiento hacia el enfermo y su cuidador en la España isabelina.

Se trata de un estudio descriptivo e interpretativo donde se irán conectando los personajes que aparecen en la escena con objeto de entender el acontecimiento que los concita. Quiénes son, porqué están y que papel representan.

La obra fue presentada por Roldan en Exposición Nacional 1864. Se encuadra en el género costumbrista sevillano, reflejo de una sociedad de marcada religiosidad con gusto por las procesiones y las obras de caridad, de las festividades y celebraciones ciudadanas.

En la pintura analizada la representación no es casual, están todos los que son y son todos los que están. La enfermería, aún sin voces propias que la expresen públicamente, justifica su presencia en tanto en cuanto hay una persona, enferma en este caso, que necesita de sus cuidados. La satisfacción de sus necesidades vitales es la argumentación.

Palabras clave: Cuidados enfermería. Cuidado humano. Historia de la enfermería. La enfermería en el arte. Arte y cuidados. Representación de la enfermera. Iconografía.

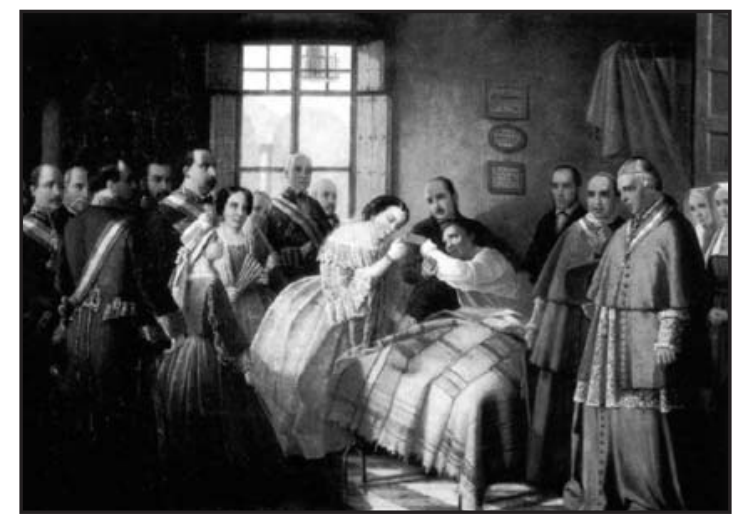

JOSÉ ROLDÁN. Su majestad la reina Isabel II en el acto de besar la mano al pobre más antiguo del hospital de la Caridad de Sevilla, ca 1864. Oleo sobre lienzo, $63 \times 83 \mathrm{~cm}$. Sevilla, Hermandad de la Santa Caridad

\section{PREÁMBULO}

Hoy día solamente contamos cuentos a los niños, la necesidad adulta de entretenimiento ha desterrado de nuestras practicas habituales el contar cuentos o leerlos en voz alta.

Sin embargo ésta ha sido una actividad favorita y común de la historia humana. Los relatores contaban tanto fábulas como sucedidos y con el tiempo, a esta necesidad del cuento se le unió la de contemplar lo narrado. Necesidad que para algunos privilegiados encontraba su satisfacción en la pintura.

Pero estampar la pura imagen se hace insuficiente para la representación costumbrista. Se espera de la imagen que reemplace, que transmita gestos y que además los aclare, buscamos entender el lenguaje corporal, los formalismos específicos del momento, las emociones y pasiones del alma de las figuras representadas. Tratando de esta manera que el conjunto de elementos que acopia nuestra visita nos permitan entender el discurso, lo abstracto de la reproducción. 


\section{LA OBRA EN SU CONTEXTO}

Durante este siglo XIX la pintura sevillana(1) vive un de sus momentos mas fecundos e interesantes enmarcándose con rasgos propios dentro del panorama artístico español.

Su producción más abundante y genuina se manifiesta a través de la temática costumbrista que fija su atención en edificios, catedrales, castillos, y palacios característicos, en ambientes que reflejen lo tradicional del pueblo llano en tanto que auténtico(2).

Por eso, en palabras de Reina Palazón "No es gratuito por tanto, que los cuadros costumbristas lleven el título de Feria de Mairena o Santiponce o que se represente el Corpus o la Semana Santa de Sevilla, pues no es tan sólo la notificación de unos personajes, sino que su adscripción a una ciudad o región pregona su caracterización singular".

\section{EL ACONTECIMIENTO}

El artista representa un acontecimiento histórico que puso a la capital hispalense en el candelero nacional. El evento fue el viaje que realizaron los reyes, la reina Isabel II y su marido Francisco de Asís de Borbón rey consorte, por las provincias andaluzas entre los meses de septiembre y octubre de 1862.

En el programa del viaje de los reyes, se incluía la visita que debía realizar la reina, a su paso por Sevilla, al Hospital de la Hermandad de la Santa Caridad.

Esta Hermandad la fundó Miguel de Mañara (4) hacia el 1662, y como la reina había sido nombrada Hermana Mayor Honorífica de la Hermandad debía de cumplir el rito anual de besar la mano del enfermo mas antiguo del hospital.

Francisco Tubino(3) redactó, en 1862, la crónica del viaje por las provincias de Jaén, Córdoba, Sevilla, Cádiz, Granada, Málaga y Almería, ofreciendo cuadros de los actos más representativos: visitas, asistencia a bailes y teatros, etc.

\section{LA ESCENA}

Sucede en una de las enfermerías del Hospital del hospital. Roldan interpreta el momento exacto en el que la reina, cumpliendo con el rito anual, acude al Hospital de la Caridad en Sevilla para saludar al enfermo mas antiguo.

Ceremonia que se lleva a cabo en presencia de todo el séquito, civil y eclesiástico, tal como queda inmortalizado en la obra.

\section{LOS PERSONAJES}

Además de que las actitudes de los personajes están relacionadas con las condiciones sociales, destaca la luminosidad del enfermo y la reina determinan el centro de la escena.

Mas que la luz es la penumbra de la izquierda la que nos permite calcular, admirable contraste entre el tono de la vestimenta de la reina, y el camisón del enfermo y los tonos neutros de los demás personajes. Toda la composición tiene su ritmo en la aparente actitud estática de los personajes.

Él, es un hombre anciano que reposa en la cama. Lleva puesto un camisón, prenda interior, que fácilmente confeccionaron las mismas monjas de la Hermandad. El camisón (visión nocturna de la camisa) blanco, típica vestimenta masculina habitual para dormir que desaparece progresivamente en los años veinte a favor del pijama(5) (Toussaint-Samat, 1994).

Es un pobre acogido por la Hermandad, y está enfermo, se nos presenta sin fuerzas para mantenerse incorporado. Seguramente uno de los hermanos de la Hermandad es el que le ayuda a incorporarse y a ofrecer su mano a la reina, manteniéndosela para el saludo.

Es el que lleva más tiempo ingresado en el hospital. Estas son las particularidades que le hacen ser el candidato para recibir una visita personal de la reina de España en la que se incluye el saludo regio.

Entre las celebridades que acompañan a la reina formando su séquito, destacan los duques de Montpensier. Antonio María Felipe de Orleáns y la infanta Luisa Fernanda, hija del rey Fernando VII y María Cristina de Borbón, por lo tanto hermana menor de Isabel II. Personajes que defendieron de los valores tradicionales de "lo español", llegando a ser buenos coleccionistas y protectores de la mayoría de los pintores sevillanos de la época.

Al otro lado de la escena, las personalidades eclesiásticas. En primer lugar, el padre Antonio María Claret, nombrado en 1857 confesor de la reina Isabel II, y que acompaña a la reina en su viaje por Andalucía. Detrás el entonces arzobispo de Sevilla Don Luís de la Lastra y Cuesta. 


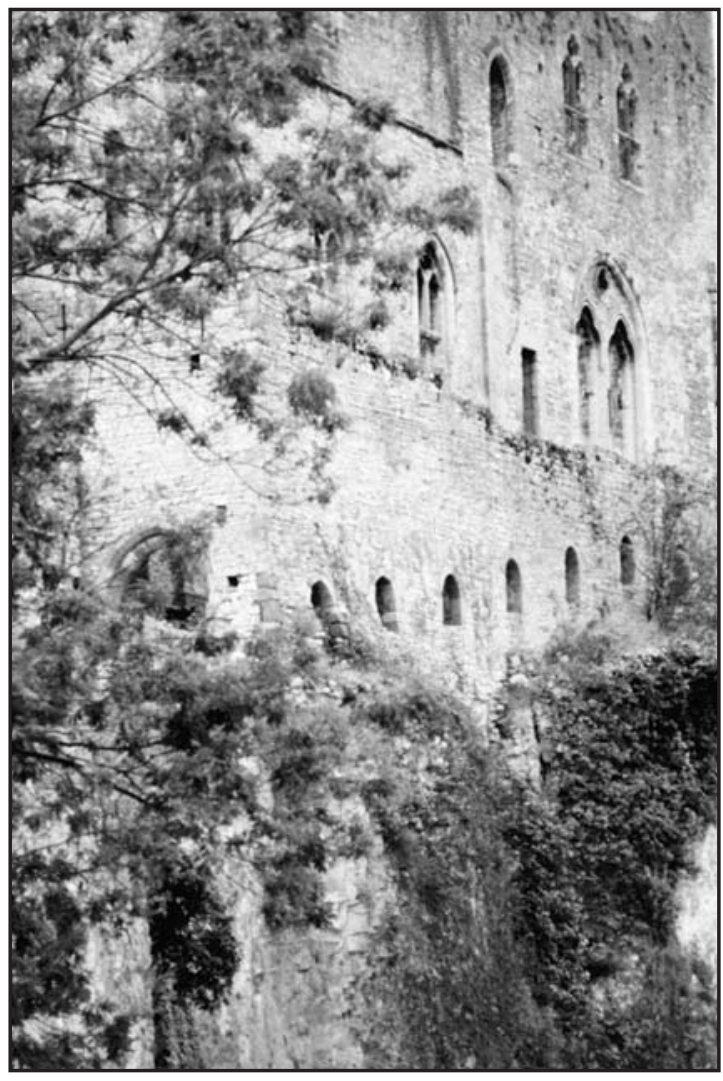

En último lugar de la escena, las más lejanas a la vista del espectador aparecen dos religiosas, miran con admiración la escena, iiLa reina ha venido y está besando al enfermo!!

\section{LA ESTANCIA}

Partiendo del centro al que nos fuerza vista de la obra de Roldan, percibimos la sencilla cama, sin pies ni cabecero, pero provista de cortinilla, que pende de lo alto y que le permitirá una pizca de intimidad en algún momento. La cama está vestida. Sábana blanca y manta de lana en jirones. Posiblemente también fuera confeccionada por las mismas monjas con los jirones, recortes sobrantes enviados desde algún telar de zona como caridad, terminada en flecos y sin remate.

El decorado de los muros de la habitación es sobrio. De la pared penden tres marcos, quizás con alguna oración, bendición o plegaria. El suelo está enlosado, habitual para las clases populares.

A la izquierda de la imagen se adivina un oratorio, no era extraño para la época que estuviera cercano a las salas de enfermos. Los conceptos, tanto de la salud como de la enfermedad tenían un gran componente religioso.

La habitación no es grande, la escena ocupa gran parte del espacio que se ilumina desde la ventana de la izquierda, que no vemos. A través de la del fondo alcanzamos a ver la otra fachada del edificio al otro lado del patio. A la derecha de la imagen, la puerta por donde entra la comitiva, que se ha quedado abierta.

\section{PROTOCOLO, EL SIGNO COMO METÁ- FORA}

El protocolo, es una de las reminiscencias de la elegancia. Es un conjunto de patrones que controlan la secuencia de mensajes que ocurren durante una comunicación entre entidades que forman una red. El protocolo hace las veces del director en una orquesta en que cada músico cumple su función y juntos consiguen una magnífica composición. Si uno va a destiempo la pieza es un desastre

En nuestro protocolo el saludo con la mano es el saludo universal. Pero en la escena que estamos presenciando el movimiento de las manos va más allá. La reina se inclina y besa la mano del enfermo. Besar la mano, también en nuestro protocolo es signo de admiración y respeto. Es mas, la mano que queda encima significa dominio, la que está por debajo sumisión.

La reina cede su lugar, dando primacía al enfermo al ir hacia él. Pero no solamente va a su dormitorio a saludarle, se inclina y le besa la mano. El beso en la mano con tolerancia y cortesía. Los reyes nunca se inclinan ante sus súbditos, la norma es que sean estos los que rindan pleitesía y se agachen. En este caso la reina va hacia el enfermo, le ofrece saludo respetuoso, se inclina y agacha su cabeza para besar complacientemente la mano del hombre enfermo.

Creo que en este caso, es más una señal de cariño y afecto. La reina Isabel II fue persona desprendida y espléndida. Su popularidad quedaba potenciada por su innata generosidad. Puede que no sea exagerado afirmar que Isabel II fue la reina más popular de la historia de España. Con frecuencia le acompañaron las aclamaciones o los piropos de su pueblo, a los que siempre supo corresponder con peculiar elegancia. 


\section{ENFERMERA}

La enfermera, en este caso una religiosa participa como actor social, disfruta del evento y participa en ello como el resto de los presentes. Aunque es la última de la escena, pero se encuentra. Y se muestra no de casualidad, en la obra están todos los que son y son todos los que están. Su presencia se justifica en tanto que aparece un hombre en calidad de enfermo, en condición de tal. Si realmente es enfermo y está atendido, serán enfermeras o enfermeros los encargados de su cuidado. Por eso están. Ahora bien, la participación social de los actores varía según su estamento, esa es la causa de que las enfermeras estén al final del recorrido de nuestra mirada. En esta representación son las últimas.

\section{BIBLIOGRAFÍA}

1 - Dentro de este ambiente de exaltación religiosa, a los pintores y escultores, que todavía no son del todo independientes, se les contrata y se les paga para representar la idea del mecenas, y son varios los temas recurrentes los reyes, la devoción eucarística, la Inmaculada Concepción de María, los santos locales, las nuevas canonizaciones. Es lógico pensar que muchas de las obras de la época fueran encargos de mecenas que pertenecieran a la iglesia, a cofradías y conventos.

2 - Reina Palazón, A. (1979): Pintura costumbrista sevillana (1830-1870). Universidad de Sevilla. Sevilla

3 - Tubino, Francisco María. (2007) Crónica del viaje de SS. MM. y AA. RR. a las provincias andaluzas en 1862 . Extramuros Edición. Sevilla.

4 - La Hermandad de la Santa Caridad remonta sus orígenes hasta la Edad Media, se tiene constancia de su existencia desde mediados del siglo XV. Cuando en 1662 Don Miguel Mañara, aristócrata sevillano, fundó de la Hermandad Santa Caridad llevaba en su mente el propósito de crear un hospital que sirviera para atender a los numerosos enfermos y mendigos que abundaban abandonados en las calles de Sevilla.

5 - Toussaint-Samat, Maguelonne. (1994) Historia técnica y moral del vestido. Alianza Editorial. Madrid.

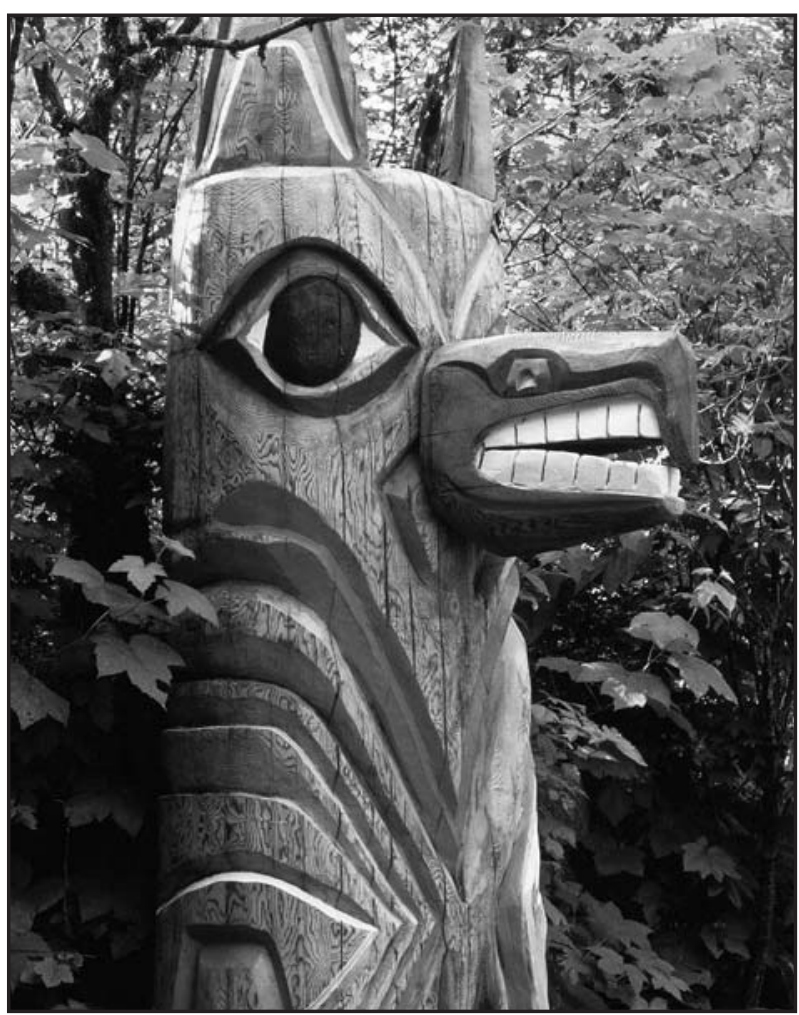

